\title{
A Case Study in Corporate E-Learning
}

\author{
http://dx.doi.org/10.3991/ijac.v8i1.4438 \\ Amy Wong ${ }^{1}$ and Karin Sixl-Daniell ${ }^{2}$ \\ ${ }^{1}$ GlobalNxt University, Kuala Lumpur, Malaysia \\ ${ }^{2} \mathrm{MCI}$ University of Applied Sciences, Innsbruck, Austria
}

\begin{abstract}
This case study introduces a corporate e-learning initiative in an India-based multinational company in the IT sector. The company provides consulting, enterprise, and telecom solutions across various industries such as banking and finance, energy and utilities, healthcare and life sciences, manufacturing, public sector and government, retail, media and entertainment, travel, transportation and logistics, and telecommunications and information technology. It employs more than 95,000 employees across 51 countries and has an established talent management and development program in place. In recent years, the company has effectively incorporated e-learning in the training and development of a selected pool of talent that is being groomed to take up various leadership positions within the corporation.
\end{abstract}

Index Terms - Corporate Learning, E-learning, India, IT.

\section{INTRODUCTION TO CORPORATE E-LEARNING}

E-learning in corporations is as a type of online training that supports both an individual as well as the organization's learning goals. Organizations need to respond swiftly to rapid changes in their external environments [1]. Ongoing training needs make it necessary to have a learning environment that combines professional progress as well as the acquisition of skills and competencies [2]. In order to attain the organization's strategic goals, companies can invest in online training programs to help employees improve their job performance, engagement and satisfaction [3]. In addition to creating a globally trained and competitive work force, organizations can use elearning as an effective means of communicating, training, development, and enhancing employee value. E-learning, through the effective use of technology, can add to skill and competency acquisition as well as career development of employees $[4,5]$. Given the estimate that half of the job skills and knowledge currently in use will be obsolete in three to five years' time [6], e-learning can be an efficient and effective way to update and enhance skill sets, competencies and knowledge within an organization's workforce as it can cater to varying learning styles.

\section{BENEFITS AND LIMITATIONS OF CORPORATE E- LEARNING}

There are many well documented benefits of e-learning, including reduced overall costs, reduced time spent on training (i.e., no travel time), the opportunity of updating content on a continuous basis, effective and efficient training of employees in geographically dispersed areas and across time zones, enhanced learning time, flexibility, increased retention, consistent delivery of content across sections, expert knowledge of facilitators, better documentation and visibility, interactivity one-on-one with professors and interaction with peers within the discussion boards, and the portability of the training (i.e., tablet/iPad, laptop, mobile phone that can be used for downloading files or assessing video and webinar links, etc.). Elearning is often perceived as a more up-to-date and flexible way of training by many employees [7] and newly acquired knowledge and skills can be put to use in the workplace almost immediately.

Despite the benefits, some senior executives are hesitant to use e-learning as a tool to educate their employees. Some of the reasons for not using e-learning are its newness, a lack of knowledge about the learning tools, the upfront investment in the course content and learning management system (LMS), possible technology and connection issues, the lack of social interaction and faceto-face contact of e-learning and a general resistance to change due to fear of the unknown. In order to implement e-learning effectively, organizations need to understand these limitations and work out a plan to overcome these challenges as well as effectively embrace the advantages that e-learning can offer.

\section{TECH MAHINDRA - A CASE STUDY}

Tech Mahindra Limited, part of the Mahindra Group conglomerate, is an Indian multinational IT company providing consulting, enterprise, and telecom solutions across various industries such as banking and finance, energy and utilities, healthcare and life sciences, manufacturing, public sector and government, retail, media and entertainment, travel, transportation and logistics, and telecommunications and information technology. Tech Mahindra is a USD 3.4 billion company with more than 95,000 employees across 51 countries.

At Tech Mahindra, there is an established talent management and development program in place, where talent employees are ranked in terms of performance and competencies via a careful process of internal nomination and screening, resulting in a selected pool of talents being groomed to take up various leadership positions within the corporation.

Tech Mahindra, working with GlobalNxt University, has recently implemented a customized corporate elearning program for their " 1,000 Leaders" training program. GlobalNxt University (formerly Universitas 21 Global, or U21Global) is a Malaysian-based online graduate school with over 9,000 students from 72 countries. The university offers the Masters of Business Administration, Masters of Science in Information Technology, as well as the Post Graduate Diploma. The university also develops and offers customized corporate programs for organizations to meet their specific talent and skill development requirements. 


\section{A CASE STUDY IN CORPORATE E-LEARNING}

As corporate e-learning offers effective, low cost, immediate, consistent and concise training that allows employees to complete training conveniently at off-hours, from home locations, while traveling, at their own pace, in an interactive, comprehensive, and engaging manner [8], it is a suitable learning tool for the talent employees of global organizations such as Tech Mahindra. At Tech Mahindra, a group of talent employees are enrolled in the customized Certificate in Global Business Leadership program, an online program with six modules, namely International Business Environment, Leadership Essentials, Managing Financial Performance, Marketing and Customer Relationship Management, Strategic Management for Innovative Business, and Entrepreneurship.

The modules are delivered over a period of 5 months, with three weeks dedicated to each module (one week reading week and two weeks of asynchronous discussion board activities and synchronous webinars) and a final two weeks break at the end of the course for completion of the final integrative project. The program is delivered through a series of online teaching tools such as webinars, discussion boards, chats, online content, case studies, assignments, animations, self-assessment activities, and videos.

In order to benefit from the e-learning experience, participants must be able to retain the new skills and knowledge. To achieve this, the program uses a variety of learning activities and media tools for participants with different learning styles (i.e., visual, auditory, kinaesthetic, or environmental). The learning activities encourage participants to apply, practice, paraphrase, and demonstrate the new skills and knowledge in different contexts. As such, participants are able to construct new knowledge via the collaborative and problem-solving activities.

There was a high degree of interaction between the professor and the participants as well as among the participants. For example, in a class of 167 participants, about 75 percent actively participated, posting more than 1,800 discussion board contributions during the first module. This reinforces the participants' dedication towards the program and their personal professional development.

The participants valued the program flexibility, both in time and location, as well as the interactivity one-on-one with professors and interaction with peers within the asynchronous discussion boards. On average, about 75 percent of the participants attended the weekly synchronous webinar sessions, with the majority of them participating actively in the webinars and Q\&A sessions, clarifying doubts and posing new questions. Several additional discussion board topics were initiated by the participants themselves, as they seek to involve their peers in matters of interest to them. The learners become independent, self-directed participants in the learning process, contributing and learning from others, to create new knowledge. As such, learning is seen as an active, contextualized process of constructing knowledge through personal experiences (i.e., social and cultural factors), peer interaction, and different learner interpretations.
Initially, some participants were hesitant about the program as they have not been exposed to the technology before, and there was a general resistance to change due to fear of the unknown. Further, some of the participants have been away from college for years and find it difficult to resume their studies and this is made worse with the newness of e-learning. This can be seen in participant feedback such as "it took me days to overcome my starting phobia". However, the incorporation of authentic tasks, experiences, settings and assessments coupled with the presence of the professor enabled even reluctant students to share, collaborate and communicate in a nonthreatening environment, and to benefit from the a/synchronous yet extremely interactive learning environment.

Indeed, Tech Mahindra has successfully used corporate e-learning as an effective means of communicating, training, development, and enhancing employee value, as seen in the following participant feedback such as "it is a really great learning experience", "it evokes our learning throughout the module", "it emphasize hands-on, realworld experiences", and "I strongly believe the professor's encouragement and motivation were instrumental and key in having this wonderful learning experience". In order to create competitive advantage and attain organizational goals, companies can consider investing in similar online training programs to help their talent employees improve their job performance, engagement, and satisfaction.

\section{REFERENCES}

[1] Coetzer A., Perry M. Factors Influencing employee learning in small businesses. Education + Training, 50(8), 2008, pp. 648-660.

[2] Fan C.S., Wei X.: Training and worker effort: A signaling perspective. The Canadian Journal of Economics, 43(2), 2010, pp. 604-621

[3] Chen, E. T. Successful e-learning in corporations. Communications of the IIMA, 8(2), 2008, pp. 45-54.

[4] Pantazis C. Maximizing e-learning to train the $21^{\text {st }}$ century workforce. Public Personnel Management, 31(1), 2002, pp. 21-26

[5] Ong C., Lai J., Wang Y. Factors affecting engineers' acceptance of asynchronous e-learning systems in high-tech companies. Information \& Management, 41(6), 2004, pp. 795-804

[6] Zhang D., Nunamaker J. Powering e-learning in the new millennium: An overview of e-learning and enabling technology. Information Systems Frontiers, 5(2), 2003, pp. 207-218 http://dx.doi.org/10.1023/A:1022609809036

[7] Batalla-Busquets J., Pacheco-Bernal C. On-the-Job E-Learning: Workers' Attitudes and Perceptions. The International Review of Research in Open and Distance Learning. 14 (1), 2013

[8] Kumar, P., \& Gulla, U. Corporate e-learning: Possibilities, promises, and realities. Journal of Library and Information Technology, 31(3), 2011, pp. 179-188. http://dx.doi.org/10.14429/djlit.31.3.987

\section{AuTHORS}

Amy Wong is with GlobalNxt University, Kuala Lumpur, Malaysia (eamy.wong@globalnxt.edu.my).

Karin Sixl-Daniell is with MCI University of Applied Sciences, Innsbruck, Austria (karin.sixl@mci.edu).

Submittted 01 February 2015. Published as resubmitted by the authors 10 March 2015. 